\title{
EVASÃO NO CURSO DE LICENCIATURA EM CIÊNCIAS BIOLÓGICAS DA UESC NA TRANSIÇÃO DO VESTIBULAR PARA O SISU (2012-2014)
}

\author{
Dropout in Biological Sciences licenciate at UESC in the transition from the entrance \\ exam to SISU (2012-2014)
}

\section{Deserción en la licenciatura en Ciencias Biológicas de UESC en la transición del examen de ingreso al SISU (2012-2014)}

\section{Ludmila César Simões*}

Maíra Tavares Mendes ${ }^{* *}$

\begin{abstract}
Resumo
A Educação Superior brasileira tem se deparado crescentemente com o fenômeno da evasão, cujas causas variam desde questões institucionais (pedagógicas, curriculares, políticas de permanência) a aspectos econômicos, sociais e familiares. Este estudo de caso objetivou compreender o fenômeno da evasão dos alunos matriculados no Curso de Licenciatura em Ciências Biológicas da Universidade Estadual de Santa Cruz (UESC), nas três turmas ingressantes de 2012 a 2014, em meio à transição da forma de ingresso do exame vestibular para o SISU. Buscando compreender a pronunciada taxa de evasão no ano de 2013, foram entrevistados estudantes evadidos com o intuito de elencar suas motivações para a saída do curso. Trabalhou-se com a hipótese de que a transição do vestibular para o SISU e o fato de ser um curso de formação de professores são fatores preponderantes para esse movimento de saída. As entrevistas confirmaram as hipóteses, bem como apontaram os seguintes fatores como contributivos à evasão do curso analisado: questões materiais, dificuldades pedagógicas, falta de identificação com o curso, carga horária extensa, dentre outras. Por fim, apresenta-se um conjunto de medidas que possibilitam aperfeiçoar as políticas de permanência a partir dos casos analisados.
\end{abstract}

PALAVRAS-CHAVE: Acesso à Educação Superior. Permanência estudantil. Evasão na graduação. Formação de professores.

\begin{abstract}
Brazilian Higher Education has been increasingly facing the phenomenon of dropout, whose causes range from institutional issues (pedagogical, curricular, permanence policies) to economic, social and family issues. This case study has aimed to understand the phenomenon of dropout in Biological Sciences Licenciate at Santa Cruz State University (UESC) from 2012 to 2014, amid the transition from entrance exams to SISU. In order to understand the outstanding dropout rate in 2013, college dropouts have been interviewed in order to inquire their motivations for leaving the

\footnotetext{
*Mestre em Biologia e Biotecnologia de Microorganismos. Pesquisadora egressa da Universidade Estadual de Santa Cruz (UESC). E-mail: ludcsimoes@ gmail.com. Orcid:https://orcid.org/0000-0001-5721-5959

*** Doutora em Educação. Professora vinculada à Universidade Estadual de Santa Cruz (UESC). E-mail: mtmendes@uesc.br. Orcid: https://orcid.org/0000-0003-1697-3133
} 
course. It has been hypothesized that the transition from the entrance exam to the SISU and the fact hat it is a teacher training course to be major factors for this outgoing movement. The interviews have confirmed the hypotheses, as well as indicated the following factors contributing to dropout in the analyzed course: material issues, pedagogical difficulties, lack of identification with the course, extensive workload, among others. Finally, a set of measures is presented in order to enable the improvement of permanence policies based on the analyzed cases.

KEYWORDS: Access to Higher Education. Student permanence. Undergraduate dropout. Licentiate.

\section{Resumen}

La educación superior brasileña se ha enfrentado cada vez más al fenómeno de la deserción universitaria, cuyas causas van desde cuestiones institucionales (pedagógicas, curriculares, políticas de permanencia) hasta cuestiones económicas, sociales y familiares. Este estudio de caso tuvo como objetivo comprender el fenómeno de la deserción de los estudiantes de la Licenciatura en Ciencias Biológicas de la Universidad Estatal de Santa Cruz (UESC), en los tres grupos que ingresaron de 2012 a 2014, en medio de la transición de los exámenes de ingreso al SISU. Para comprender la pronunciada tasa de deserción en 2013, estudiantes evadidos fueron entrevistados para averiguar sus motivaciones para abandonar el curso. Se planteó la hipótesis de que la transición del examen de ingreso al SISU y el hecho de que es un curso de formación docente son factores importantes para este movimiento de salida. Las entrevistas confirmaron las hipótesis, así como los siguientes factores que contribuyen a la deserción del curso analizado: cuestiones materiales, dificultades pedagógicas, falta de identificación con el curso, gran carga de trabajo, entre otros. Concluyimos presentando un conjunto de medidas para mejorar las políticas de permanencia en el caso analizado.

PALABRAS-CLAVE: Acceso a la Educación Superior. Permanencia estudiantil. Deserción en la graduación. Formación de profesores.

\section{INTRODUÇÃO}

A evasão escolar é um fenômeno que tem ocorrido em larga escala e tem sido bastante discutido no Brasil. Inicialmente abordado no âmbito das escolas, com o crescimento da quantidade de universidades esse fenômeno passou a ter maior atenção também nesses espaços. Contraditoriamente, apesar do grande déficit de professores no Brasil, esse processo é comum também em cursos de formação de professores.

Segundo Bardagi, Hutz (2009) e Santos (2014) as universidades de modo geral abordam a evasão como se ela fosse causada exclusivamente por questões pessoais dos alunos. Esta argumentação é contestada por diversas pesquisas que apontam para a influência da gestão e da organização do curso (currículo, carga horária, professores) na evasão (ALMEIDA, 2009; SANTOS, 2014).

Este trabalho visa compreender o fenômeno da evasão dos alunos do Curso de Licenciatura em Ciências Biológicas da Universidade Estadual de Santa Cruz (UESC), nas três turmas ingressantes de 2012 a 2014 do turno diurno. A escolha do ano de 2013 se dá em virtude de ter sido o primeiro ano em que a seleção para a universidade se deu 
exclusivamente via Exame Nacional do Ensino Médio (ENEM), por meio do Sistema Único de Seleção Unificada (SISU). Foram incluídas na análise as turmas de 2012 (quando metade da seleção para o ingresso aconteceu via SISU e a outra metade pelo Vestibular) e também o ano de 2014, para comparação e melhor compreensão do fenômeno ocorrido em 2013.

Trabalhou-se com a hipótese de que a transição do vestibular para o SISU e o fato de ser um curso de formação de professores são fatores preponderantes para esse movimento de saída. Para verificar sua validade, foram realizadas 16 entrevistas junto a evadidos do Curso de Licenciatura em Ciências Biológicas que ingressaram entre os anos de 2012 e 2014. Realizamos uma pesquisa exploratória, de abordagem predominantemente qualitativa, utilizando a técnica da Análise de Conteúdo (BARDIN, 1977).

\section{Evasão: conceituação e motivações}

A evasão, de forma geral, é vista como a interrupção do ciclo de estudos (GAIOSO, 2005). Entretanto, existem inúmeras definições que são encontradas na literatura. Ela pode ser vista pelo ângulo da permanência do aluno no Ensino Superior em que se considera a evasão do curso, na qual o aluno evade sem concluí-lo, e a evasão do sistema, em que há o abandono do Ensino Superior (BRASIL, 1996). Há ainda a evasão aparente, que é a mobilidade de um curso para o outro, em contraste com a evasão real, na qual há a desistência do aluno em cursar a Educação Superior (CARDOSO, 2008).

Uma vez que este trabalho tem como foco o Curso de Licenciatura em Ciências Biológicas de uma única universidade, estamos considerando a evasão como o desligamento definitivo destes estudantes em relação ao curso analisado. Isto não significa que este estudante tenha abandonado o Ensino Superior, visto que pode ter ocorrido migração para outro curso ou outra instituição de ensino (evasão aparente).

Dentre os motivos possíveis para a evasão estão dificuldades materiais dos alunos que possuem condições financeiras desfavoráveis, associando-se a questões como: moradia distante do campus; custo de fotocópias, aquisição de livros ou outros materiais e alimentação; o uso do computador; além da necessidade de trabalhar, que diminui o tempo de dedicação disponível para os estudos (SILVA FILHO, 2007; ALMEIDA, 2009; BARDAGI; HUTZ, 2009; SANTOS, 2014).

Outro obstáculo para os alunos mais pobres são as dificuldades simbólicas e culturais. Elas estão associadas à socialização no ambiente familiar e na trajetória de vida e de estudos. Sendo assim, tais dificuldades de cunho pedagógico podem interferir na inserção acadêmica dos alunos. Elas são definidas como: falta de conhecimentos prévios sobre assuntos do Ensino Básico; dificuldades na produção de seminários e trabalhos científicos; não compreensão de textos em línguas estrangeiras; dificuldades associadas ao domínio da língua portuguesa (GISI, 2006; ALMEIDA, 2009), bem como falta de familiaridade com a dinâmica acadêmica.

Ademais, diversos entraves que estão estritamente ligados à política da universidade são destacados. Dentre eles, a falta de políticas de permanência e assistência 
estudantil; falta de professores; pouca integração social com a universidade; horário das disciplinas; dificuldades relacionadas ao currículo ou organização da instituição; professores que não são acessíveis ou não sabem lidar com os alunos (BRAGA et al, 2003; GAIOSO, 2005; SILVA FILHO, 2007; ALMEIDA, 2009).

Além dessas, inúmeras outras questões são levantadas, a exemplo de falta de orientação vocacional; imaturidade do estudante; questões familiares; problemas de saúde; falta de identificação com o curso; baixa demanda pelo curso (que pode estar associada ao seu baixo prestígio social, como é o caso das licenciaturas), dentre outras causas (BRAGA et al, 2003; SILVA FILHO, 2007; GAIOSO, 2005; ALMEIDA, 2009; CARDOSO, 2008; BARDAGI; HUTZ, 2009; SANTOS, 2014).

Acrescida às questões ligadas ao desempenho, motivações do estudante e política institucional, a forma de ingresso também pode ter grande influência. Analisamos aqui a transição da forma de seleção do vestibular para o ENEM/SISU.

\section{Do vestibular ao ENEM/SISU}

O ENEM foi criado em 1998, quando tinha por objetivo avaliar o desempenho dos alunos do Ensino Médio e fornecer dados para a elaboração de políticas públicas e pesquisas educacionais pelo MEC. Entretanto, em 2009, o exame foi reformulado com o intuito de ser o critério de acesso às vagas do Ensino Superior. Assim, a partir de seu desempenho na prova, os estudantes passaram a concorrer simultânea e nacionalmente às vagas em instituições de Ensino Superior. Em 2010 o SISU foi institucionalizado, constituindo-se numa ferramenta eletrônica que possibilita aos participantes do exame concorrer às vagas em qualquer universidade cadastrada do Brasil, sem que haja necessidade de deslocamento para a realização das provas (LOURENÇO, 2016).

As mudanças no ENEM são apontadas como vantagens, mas são também alvo de críticas. Luz e Veloso (2014) destacam que o fundamento meritocrático que baliza os exames vestibulares permanece inalterado no SISU. Leher (2009) afirma que a unificação das provas torna a concorrência mais desleal, pois os estudantes privilegiados economicamente são favorecidos por ter se mantido a lógica de seletividade social, visto que mais pessoas de diversas regiões podem concorrer às vagas em uma dada universidade, tornando a concorrência mais agressiva. Assim, os concorrentes que moram perto da instituição, caso não consigam uma vaga no curso desejado, acabam optando por um curso que não é de sua escolha e/ou de menor prestígio; ou então optando pelo curso desejado em um local mais distante. Como resultado, os estudantes com maior poder aquisitivo podem recorrer a esta última opção; enquanto que os mais pobres tanto escolhem outro curso como, caso consigam se deslocar para universidades distantes, o fazem sem ter a permanência assegurada.

Uma pesquisa realizada no curso de Licenciatura em Ciências na UNIFESP/Diadema apontou que 55\% dos estudantes que ingressaram no curso não tinham pretensão de concluí-lo; segundo os dados de 2011 a 2014, mais da metade ingressou pela nota que lhes coube no SISU, não por preferência. Além disso, $48 \%$ dos alunos que 
evadiram nesse período disseram que pretendiam mudar de curso e/ou de universidade (RANGEL et al, 2015).

Segundo a literatura, a evasão aparente, bem como a baixa procura ocorrem em grande parte nos cursos de Licenciatura por motivos que variam desde a desvalorização social da carreira do professor, a um currículo inadequado, passando pela baixa remuneração dos docentes, dentre outros fatores (OLIVEIRA SOARES; PIRES, 2010).

Estudo realizado no curso de História da Universidade Federal de Mato Grosso do Sul (UFMS) corrobora a literatura, pois ele indica que as diversas chamadas (lista de candidatos classificados, dentro da quantidade de vagas ofertadas pelo SISU para cada curso, através da concorrência) proporcionadas pelo SISU fazem com que alunos que não tinham a Licenciatura como primeira opção entrem no curso, sendo que grande parte evade posteriormente. Ainda mais, a maioria das pessoas que evadiram dos cursos de Licenciatura e ingressaram em outra área dizem ter feito uma boa escolha. A maioria dos que evadiram e não ingressaram em outro curso se arrependem, mas dizem que não viam futuro como graduando em um curso de Licenciatura (CARVALHO; OLIVEIRA, 2014).

O SISU possui características que possibilitam ao aluno concorrer a vagas em universidades de todo Brasil e permite acesso a ações afirmativas como as cotas, fazendo com que grupos discriminados socioeconomicamente e racialmente tenham acesso à universidade. Entretanto, esta forma de ingresso na universidade quando não associada a políticas de permanência abrangentes pode fazer com que a mobilidade seja fortemente impactada pela evasão no Ensino Superior.

\section{Evasão no curso de licenciatura em Ciências Biológicas da UESC}

O Curso de Licenciatura em Ciências Biológicas da UESC possui dois ingressos anuais. O período diurno, que estudamos neste trabalho, disponibiliza 20 vagas anuais, sempre no primeiro semestre. De acordo com os dados obtidos pela pesquisa junto ao Colegiado do curso, entre 2012 e 2014 o número de alunos evadidos do curso foi de 39, o que corresponde a uma taxa de evasão de $65 \%$ para o triênio. Esta elevada taxa variou da seguinte maneira neste período: 50\% em 2012, 80\% em 2013 e 65\% em 2014.

Destacamos dentre os dados analisados o que chamamos de evasão aparente, como nos casos em que os estudantes permaneceram não apenas no Ensino Superior, mas na mesma instituição: três dos evadidos da Licenciatura migraram para o Bacharelado em Ciências Biológicas, e outros três reingressaram no curso por meio do SISU. Se considerarmos a amostra de entrevistados (16 do total de 39 evadidos), 11 afirmaram estar cursando o Ensino Superior.

\section{Ingresso exclusivo pelo SISU e efeitos na escolha do curso}

Dentre os 16 entrevistados, 12 tiveram a evasão facilitada pelas características do SISU/ENEM. Isto põe em evidência este critério de análise, visto que foi o principal motivo de evasão indicado pelos participantes. Além disso, percebe-se que 7 dos entrevistados não possuíam as Ciências Biológicas como preferência, de tal maneira que 
muitos utilizam os verbos "apostar" e "arriscar", ou a expressão "atirando para todo lado" quando se referem à escolha do curso.

Ademais, 8 estudantes afirmam terem utilizado a facilidade da ferramenta SISU pelo fato de acompanharem a nota de corte e observarem se havia ou não a possibilidade de ingressar no curso de maior interesse. Uma vez que não conseguiram vaga no curso almejado, afirmam que acabaram ingressando no curso de Licenciatura em Ciências Biológicas como uma alternativa (corroborando Rangel et al, 2015). Alda ${ }^{1}$ reforça essa ideia: "[o Sisu] facilita [a entrada na UESC], 'eu não passei em um, vou colocar em outro que eu me identifico mais"”. Elaine descreve como fez a escolha do curso pelo Sisu/ENEM:

\begin{abstract}
Minha primeira opção era Medicina, só que eu vi minha colocação, e vai atualizando os dias, não é? Quando eu vi que estava distante eu falei 'Esse tanto de gente não vai desistir não, deixa eu sair logo aqui’ [...] entre a Biologia e a Enfermagem eu preferi a Biologia [...] mas, depois da Medicina eu não sabia o que [fazer]. Então, quando eu vi a Biologia, eu falei 'Pode ser que seja isso', então eu apostei. (Elaine).
\end{abstract}

\begin{abstract}
Eu tinha dúvida antes entre a Biologia e a Veterinária, porque eu não conhecia bem as duas, então depois que eu ingressei na Biologia e vi que não era aquilo o que eu queria, tive a certeza que era a Veterinária. [...] foi mais a minha mãe que me via infeliz no curso [de Biologia] e ela falou: 'faz o Enem de novo e tenta a Veterinária', eu fiz, mas nem esperava passar em Veterinária. (Ary).
\end{abstract}

Esta mesma facilidade em acompanhar a nota de corte não existia no antigo vestibular. Observa-se que a transição da forma de ingresso interferiu nas intenções dos alunos para entrada nos cursos, pois quando ingressam em cursos que não são de sua preferência, muitos já entram sem a perspectiva de continuar. Como destaca Elena: "coloquei aqui na verdade, já pensando em sair, mas como era uma área que também gostava, a área da Biologia, então coloquei”.

Portanto, este mecanismo de escolha tem influência sobre a evasão, visto que no vestibular era mais difícil a entrada de alunos em cursos que não fossem de sua preferência. Como afirma Alda: "[O SISU] interferiu [na minha entrada no curso], por que se não fosse pelo SISU eu não tinha nem entrado. Seria o que? O vestibular normal. E se fosse o vestibular normal, eu não teria colocado Biologia, eu teria colocado em Medicina, e não teria passado em Biologia".

O SISU também facilitou que os entrevistados pudessem concorrer, pelo mesmo processo seletivo, a vagas em universidades de todo Brasil sem se deslocar das suas cidades, realizando para isso a prova do ENEM. Esta característica do SISU também pode favorecer a evasão, pois as pessoas podem concorrer às vagas em universidades que estão distantes da sua cidade de origem. Elena destaca que "como agora o SISU é no Brasil todo, se inscrevem pessoas de vários Estados, e às vezes nem vêm, e aí fica a vaga aí".

Esta intensificação da concorrência favorece estudantes já privilegiados economicamente, visto que os mais pobres têm muito mais restrições para se manter longe

1 Todos os nomes de estudantes aqui citados são fictícios para garantir seu anonimato. 
de suas famílias. É o que afirma Anita, que ingressou em 2013 e evadiu do curso principalmente pela questão financeira, mas quis voltar e não conseguiu passar no Sisu/ENEM para a Licenciatura em Ciências Biológicas:

Eu até pensei [...] será que se tivesse o vestibular eu conseguia passar? Realmente no curso de Biologia [...] as pessoas entram e saem e não é tanta gente que tenta fazer ele, a maioria das pessoas entra pela nota de corte, porque não conseguiram passar numa Medicina, foi o que eu vi lá, e colocam Biologia só pra tentar convalidar a matéria depois. Eu acho que hoje se eu fizesse um vestibular, talvez eu conseguisse passar, porque não teria uma concorrência (Anita).

Anita ressalta que estudantes que preferiam outros cursos entram em Ciências Biológicas com o intuito de convalidar as matérias semelhantes, como foi o caso de Elena: "dependendo da Universidade, poderia convalidar alguma matéria, como a Biologia Celular e Molecular, que tem a carga horária até boa".

Outros entram com o intuito de estudar para se preparar para outros cursos, como aponta Alda ("ah, eu vou estudar Biologia por que dá pelo menos pra eu fechar mais as provas de Biologia, ter mais noção de Biologia pra quando eu for tentar pra Medicina") e Yara ("eu pensei assim, se depois eu fosse fazer Medicina eu queria fazer um curso que me desse alguma base, como eu não tive afinidade por Enfermagem, então eu escolhi Biologia"). Há ainda aqueles que entram somente porque não conseguiram passar no curso de interesse, como afirma Elaine: "[O critério que eu utilizei para entrar no curso foi:] 'É, dava pra passar'".

É possível observar que a transição da forma de ingresso do Vestibular para o SISU/ENEM facilita a entrada de quem vê no Curso de Licenciatura em Ciências Biológicas uma segunda opção em relação a outros cursos, em especial o concorrido curso de Medicina. Por outro lado, ela também facilita a entrada de alunos de outras regiões, que nem sempre conseguem permanecer. As características desta forma de ingresso facilitam, ainda, a entrada de estudantes em dúvida com o curso, os quais frequentemente caem na categoria da "evasão aparente", ao migrar de universidade ou mesmo de curso dentro de uma mesma instituição. Discutiremos a seguir alguns dos motivos apontados para a migração da Licenciatura rumo a outros cursos.

\section{Falta de identificação com o curso}

A falta de identidade com o curso é uma das questões salientes nas falas analisadas: 8 dos 16 entrevistados destacam este aspecto. Grande parte dessas pessoas que não se adaptaram tinha a Licenciatura como segunda opção ou estava em dúvida entre Biologia e outro(s) curso(s). Assim, demonstram insatisfação com o enfoque, disciplinas e configuração do curso.

Identificamos ainda que há um descompasso entre o curso de Biologia na escola e as bases de formação e o campo de atuação profissional do biólogo. Estudantes que têm afinidade com a Biologia escolar acabam escolhendo o curso de Ciências Biológicas, quando poderiam ter ampliado seu leque de escolhas se tivessem tido contato com outras áreas profissionais. 
A falta de orientação vocacional e o desconhecimento sobre as profissões, incluindo a do biólogo, são marcantes, e é o que leva os alunos a terem dúvida entre as profissões que querem exercer. Segundo os entrevistados Patrick e Ana Paula:

tem uma coisa que o Ensino Médio peca bastante, que é não saber orientar qual a escolha do aluno, por exemplo, eu nunca tinha ouvido falar [...] como era o curso de Comunicação, eu só conhecia o básico, e o que a gente vê que é Português, Matemática, Biologia, Química, Física; e dentre essas, eu tinha uma afinidade com Biologia, só que quando eu conheci eu vi que essa afinidade não era forte o suficiente pra me fazer levar o curso até o final e trabalhar com isso (Patrick).

Eu achava que eu gostava [da Biologia]. É por que a gente não tem muito direcionamento na escola, a gente acha que gosta de uma matéria na escola e que na universidade vai ser a mesma coisa da escola. Só porque eu gostava na escola, eu achava que ia gostar do curso em si (Ana Paula).

\section{A desvalorização da licenciatura}

A escolha por um curso de Licenciatura é atravessada pela contradição entre ampliação do campo de trabalho e desvalorização profissional (CARVALHO; OLIVEIRA, 2014). A experiência de desvalorização de seus próprios professores é marcante nas falas de muitos entrevistados:

É um pouco complicada [a perspectiva do licenciando em Biologia] [...] quando eu entrei no curso, eu entrei apaixonada [...] mas aqui na região, principalmente aqui nessa cidade é muito difícil de desenvolver Ciências Biológicas. [...] infelizmente ensinar hoje está muito difícil, pois essa profissão [de professor] está muito desvalorizada. E, eu tiro isso, porque a pessoa que me fez admirar, sentir essa paixão pela Biologia foi minha professora do Ensino Médio [...] quando eu a via dando aula, era uma sala com quarenta e tantos alunos, ela conseguia cativar três pessoas, mas imagine você numa sala com três pessoas prestando atenção em você, mas o restante disperso, fazendo aquele barulho. Então, eu acredito que você chega a desmotivar, você tem que ser bem forte para ir até o fim (Anita).

Geilma discute o quanto a profissão é estressante em face de uma má remuneração: "era uma coisa que eu não queria mesmo dar aula para Ensino Médio, eu acho muito estressante e a profissão não é valorizada, não é? Os professores em geral não recebem muito bem, principalmente em escola". Ana Paula contrapõe a docência na escola básica à do ensino superior: "Muitas pessoas querem ser professores universitários, quem está ali dentro quer ser ou pesquisador [ou professores universitários]. Poucas pessoas realmente querem ser professores de escola de primário, no Ensino Médio, poucas pessoas querem".

Os 6 entrevistados que citaram a desvalorização social da carreira do professor e a sua baixa remuneração realizaram uma evasão aparente, abandonando a Licenciatura por outros cursos (corroborando Oliveira Soares; Pires, 2010; Carvalho; Oliveira, 2014). Ademais, a representação do ensino como "dom" inato seria, para Mailton, o fator preponderante para a evasão:

Não, não tenho $[\mathrm{dom}] . .$. acho que a pessoa nasce com talento de ensinar e eu não nasci com isso [...] eu tenho dificuldade de explicar qualquer coisa, dificuldade de estudar com meus colegas, de dar aula para os meus colegas, quando eu sabia 
mais que eles o assunto e eu ia ensinar para os meus amigos, eu não conseguia passar direito, e eu sabia, eu sentia que eles saiam assim 'Ah, não adiantou nada, não adiantou nada', mesmo eu tentando. Então, eu já não me via muito, nunca me vi nesse papel, só que dentro do curso que eu vi que não era para eu entrar ali, porque mesmo que fosse uma alternativa, não seria uma alternativa para mim, porque mesmo que eu passasse para um concurso no Município, no Estado, ou que eu fosse dar aula numa particular, eu não ia ser um bom professor, então não fazia sentido continuar na Licenciatura, só pelo a mais de eu poder dar aula, se eu não ia buscar esse a mais, se eu não ia... sabe? Então eu ia ser um professor igual aos que eu reclamava, igual aos que eu colocava defeito? Não, não (Mailton).

Apesar de as técnicas para exercer a docência poderem ser aprendidas e aperfeiçoadas com a prática, o discurso da docência inata representa outra forma de desvalorização da docência, visto que esvazia seu caráter profissional.

A decepção com a perspectiva de retorno financeiro é outro elemento conectado ao baixo prestígio social da Licenciatura, como no caso de Geilma, que decidiu mudar para uma área diferente, a Engenharia Civil.

Eu estava gostando do curso [de Biologia], eu fiz o ENEM por fazer, e eu acabei passando [em Engenharia Civil]. [...] e acabei resolvendo tentar, arriscar, para ver se era uma coisa que eu gostava (risos) porque eu não tinha certeza também se ia gostar. Às vezes eu fico um pouco arrependida, porque o curso [de Biologia] em si é bem mais divertido, bem mais legal pra mim, de cursar do que Engenharia Civil, mas eu acho que talvez iria conseguir esse retorno que queria mais rápido, com essa profissão que eu vou ter. [...] Talvez se não tivesse surgido essa oportunidade [de passar pelo ENEM em Engenharia Civil], eu continuasse e tentasse me realizar profissionalmente nessa área [da Biologia] (Geilma).

Esta atitude foi semelhante à de Sandra, que apesar de gostar de Biologia, preferiu mudar para Veterinária por almejar um retorno financeiro mais rápido para constituir família:

você pra ter emprego [licenciada em Biologia] é um pouco mais difícil, o retorno financeiro eu considerei que não era tão legal, por exemplo, pra você começar a receber um dinheirinho bom, você tinha que ir pra um mestrado, um doutorado e isso ocupa muito tempo, não que eu não queira fazer, mas eu quero ter família um dia [...] então eu decidi ir pra um curso que achei que dava um dinheiro melhor em pouco tempo [a Veterinária], assim, você se forma e ganha um dinheiro melhor (Sandra).

\section{Dificuldades pedagógicas e carga horária extensa}

Dentre os motivos mais recorrentes para evasão apontados pelos evadidos, estão as dificuldades pedagógicas, apontadas por 12 dos 16 entrevistados. São as disciplinas da área de exatas as mais mencionadas pelos estudantes. Para eles, estas dificuldades estão relacionadas à baixa afinidade com estas disciplinas, aos problemas decorrentes de falhas de formação no Ensino Médio, à "falta de didática" dos docentes, como também a 
problemas na relação com professores (incluindo o relato de casos de assédio a estudantes mulheres).

Tive muita dificuldade com Física e Química, principalmente Química. Eu fiz Química três vezes e não consegui passar, era como se fosse uma língua totalmente abstrata pra mim, não consigo entender nada de Química, tanto que Química foi um empecilho tão grande, que foi uma das coisas que me fez pensar em sair mesmo, não foi nem pela questão da Biologia, mas pelo que tem lá e que está meio distante da Biologia, pra quem não assimilava (Patrick).

Eu perdi em Química, que trancava um monte de matérias, então quando eu cheguei no segundo semestre bem desmotivada, eu já não levei tanto a sério, porque quando perdemos em alguma matéria que é importante vamos desmotivando. Então você vê toda galera adiantando e você ali, ou vai pra faculdade pra pegar uma matéria 7:00h da manhã e outra 3:00h da tarde, porque você não conseguiu pegar outras, porque está com tudo trancado. Então é meio chato você ficar o dia todo na faculdade, as vezes pra ter aula de só duas matérias, essas coisas vão te desestimulando (Sandra).

As dificuldades pedagógicas que ocasionam reprovações sucessivas podem estar relacionadas não só a dificuldades vinculadas à escola básica, como a dificuldades simbólicas e culturais no choque com o ensino superior. Isto faz com que os métodos de ensino, sobretudo de professores das disciplinas em início de curso, sejam ainda mais relevantes para estes estudantes. Portanto, uma falta de preocupação com questões pedagógicas (o que leva frequentemente à cultura de reprovação generalizada de muitas turmas) é bastante crítica para o aprofundamento da evasão. Foi recorrente o questionamento da avaliação dos professores, sobre cobrar em provas o que não é ministrado em aula, bem como o que chamam de "falta de traquejo" com os alunos.

Para além das dificuldades nomeadas como pedagógicas, incluímos como categoria de análise a posteriori a extensão da carga horária do curso, apontada por 6 dos 16 entrevistados como motivo de evasão. Chamou a nossa atenção a intensidade dos termos utilizados para qualificar esta carga horária: "extensa", "pesada", "maçante", "exaustiva", "horrível", "desumana".

As críticas dos alunos com relação à carga horária estão usualmente relacionadas a questões financeiras, pela incompatibilidade de conciliar trabalho com o curso integral.

Exaustiva, eu acho a carga horária de Biologia exaustiva, e além das áreas das disciplinas biológicas ainda têm as de Licenciatura, para quem trabalha mesmo é muito difícil. Não existe isso de trabalhar, fazer um curso de Biologia integral, não tem como, ou a pessoa abdica de algumas disciplinas para trabalhar, ou não tem não tem essa possibilidade (Geane).

Estas questões são agravadas pelos custos maiores com alimentação, como citam alguns alunos. $\mathrm{O}$ cansaço com o curso leva alguns a afirmarem que não conseguem sequer estudar em casa, ou mesmo que chegaram a dormir em sala de aula.

A gente fica muito tempo dentro da sala de aula, e em muitas dessas aulas os alunos dormem, você sabe... os alunos dormem, só estão presentes, fingem que aprendem, assinam a lista e vão embora. Isso é péssimo, porque tem professor que tem quatro horários um atrás do outro e não é dividido em prática e teórica, só teórica e ele quer dar o assunto um atrás do outro (Elaine). 


\section{Dificuldades financeiras e outras questões}

As questões relacionadas ao trabalho/ financeiras, ainda que não apareçam dentre as mais citadas pelos estudantes (apenas 3 as destacam como motivos para evasão), são um tema importante a ser analisado.

Quando você tem que se preocupar com essa questão financeira, você não se doa tanto, você tem outras preocupações, tem que se preocupar com outros meios para conseguir me manter, e quem tem essa segurança financeira não precisa se preocupar com essas coisas e consegue se dedicar um pouquinho mais. [...] te deixa um pouco preocupado também, porque nem sempre você vai ter, e você fica pensando como vai conseguir, e acaba deixando você um pouco com atenção para duas coisas, não só no estudo (Geilma)

A necessidade de abandonar o curso para trabalhar demonstra um aspecto mais crítico da desigualdade de classe, porém outras formas mais sutis também são indícios dessas dificuldades. Como destacamos mais acima, a extensão da carga horária é uma delas - impossibilitando conciliação entre trabalho e estudos, levando estudantes que não tem a opção de serem sustentados pela família à evasão.

Eu achava que tinha muitos espaços [de horários] vagos, então, se você tivesse uma oportunidade de emprego à tarde, você não podia, tinha que ficar o dia todo aqui e às vezes eu tinha aula até dez horas e ia ter aula de novo três horas da tarde, então acabava que não tinha muita necessidade de ficar aqui o restante do dia. E não tinha aula, e você acabava perdendo a oportunidade de fazer outras coisas. [...] Eu ficava um tempão no bosque esperando o tempo passar, e acabava atrapalhando (Irismara).

Outra questão bastante recorrente são as limitações das políticas de permanência na universidade, ensejando críticas ao atraso, valor e número restrito de bolsas, ou à precariedade do restaurante universitário. São ainda pronunciadas as queixas relativas ao custo e tempo de deslocamento até o campus; custo com alimentação e com materiais do curso (xerox, livros, jalecos, trabalhos de campo).

O relato de problemas de saúde, seja dos próprios estudantes, seja de seus familiares, completam o conjunto de motivações apontadas para a desistência do curso.

\section{CONSIDERAÇÕES FINAIS}

Este trabalho discute as motivações para evasão do Curso de Licenciatura em Ciências Biológicas da UESC no período diurno, entre 2012 e 2014, com destaque para a forma de ingresso por meio do ENEM/SISU. Foi possível identificar que a busca preferencial por cursos de alto prestígio, como a Medicina, atrai atenção a cursos da mesma área de concentração (Ciências Biológicas), levando ocasionalmente ao ingresso em cursos com menor nota de corte, como os de licenciatura. A falta de identidade de modo geral com o curso de Biologia, bem como especificamente a desvalorização social da Licenciatura, são apontadas como razões relevantes para a evasão, levando os estudantes a realizar um novo processo seletivo na busca do ingresso em cursos mais afins aos seus 
interesses. Isto nos leva à discussão de que grande parte do que é considerada evasão pela instituição é na verdade mobilidade, facilitada pelas características do ENEM/SISU.

São ainda destacadas as motivações ligadas a dificuldades pedagógicas, sobretudo no início do curso. Sobre estas dificuldades, destacamos sugestões como a criação de turmas adicionais de disciplinas com alto nível de reprovação, especialmente para disciplinas pré-requisitadas, visando regularização do fluxo; instituição e ampliação de monitorias ou outras formas de atendimento das dificuldades relacionadas aos conteúdos do Ensino Médio; reavaliação dos currículos, tendo em vista a extensão de carga horária, e de metodologias utilizadas pelos docentes, assim como exame dos principais pontos de retenção no curso.

Acredita-se assim, que a evasão é um fenômeno que pode ser influenciado por causas compartilhadas com outras instituições, mas que tem suas particularidades. Dessa forma, é imprescindível que pesquisas sobre a evasão sejam realizadas, para que sejam elucidadas suas causas e medidas venham ser colocadas em prática para assegurar a permanência dos estudantes nas instituições.

\section{REFERÊNCIAS}

ALMEIDA, W. USP para todos? Estudantes com desvantagens socioeconômicas e educacionais e fruição da universidade pública. ed. São Paulo: Musa Sociologia, 2009.

BARDAGI, M.; HUTZ, C. "Não havia outra saída": percepções de alunos evadidos sobre o abandono do curso superior. Psico- USF, v. 14, n. 1, 2009.

BARDIN, L. Análise de conteúdo. Lisboa: Edições 70, 1977.

BRAGA, M.; PEIXOTO, M.; BOGUTCHI, T. A evasão no ensino superior brasileiro: o caso da UFMG. Avaliação. São Paulo, v. 8, n. 1, p. 161-189, 2003.

BRASIL. Diplomação, retenção e evasão nos cursos de graduação em instituições de Ensino Superior públicas. Brasília: SESU/MEC / ANDIFES /ABRUEM, 1996.

CARDOSO, C. Efeitos da política de cotas na Universidade de Brasília: uma análise do rendimento e da evasão. 2008. Dissertação (Mestrado em Educação) - Universidade de Brasília, Brasília, 2008.

CARVALHO, C.; OLIVEIRA, V. Evasão na licenciatura: estudo de caso. Revista Trilhas da História. Três Lagoas, v.3, nº 6, p.97-112, jan./jun. 2014.

GAIOSO, N. P. de L. O fenômeno da evasão escolar na Educação Superior no Brasil. 2005. Dissertação (Mestrado em Educação) - Programa de Pós-Graduação em Educação da Universidade Católica de Brasília, Brasília, 2005. 
GISI, M. L. A Educação Superior no Brasil e o caráter de desigualdade do acesso e da permanência. Diálogo Educacional, Curitiba, v. 6, n. 17, p. 97-112, 2006.

LEHER, R. Educação no capitalismo dependente ou exclusão educacional? In:

MENDONÇA, Sueli Guadalupe de Lima; SILVA, Vandeí Pinto da; MILLER, Stela (Org.). Marx, Gramsci e Vigotski: aproximações. 1ed. Marília: Junqueira \& Marin; Cultura Acadêmica, 2009.

LOURENÇO, V. Limites e possibilidades do ENEM no processo de democratização do acesso à Educação Superior brasileira. Tese (Mestrado em Educação) - Universidade de Brasília, Faculdade de Educação, Brasília, 2016.

LUZ, J. N. N.; VELOSO, T. C. M. A. Sistema de Seleção Unificada (SiSU): Refletindo sobre o Processo de Seleção. Educação e Fronteiras On-Line, Dourados-MS, v. 4, n. 10, p. 68-83, jan./abr. 2014.

RANGEL, F.; CEICATO, I.; STOCO, S.; BROCKINGTON, J.; TESTONI, L.; SILVA, J. Evasão e vulnerabilidade acadêmica numa licenciatura em ciências. Anais do X Encontro Nacional de Pesquisa em Educação em Ciências, Águas de Lindóia, SP, 2015.

SANTOS, P. Abandono na Educação Superior: um estudo do tipo Estado do Conhecimento. Educação por Escrito, Porto Alegre, v. 5, n. 2, 2014.

SILVA FILHO, R. A evasão no ensino superior brasileiro. Cadernos de Pesquisa, São Paulo, v. 37, n. 132, p. 641-659, 2007.

OLIVEIRA SOARES, Christiane Assis; PIRES, Luciene Lima de Assis. A formação de professores no Brasil e o curso de Licenciatura em Física do IFG Campus Jataí: em estudo sobre a evasão e a repetência. Anais da Semana de Licenciatura, Jataí-GO, p. 135-144, nov. 2010. Disponível em: <http://revistas.ifg.edu.br/semlic/article/view/347/147>. Acesso em: 09 dez. 2019.

Recebido em: 11/12/2019

Aprovado em: 28/02/2020 